\title{
Lymph Node Clearance after Total Mesorectal Excision for Rectal Cancer: Laparoscopic versus Open Approach
}

\author{
George Pechlivanides $^{a} \quad$ Nikolaos Gouvas $^{b} \quad$ John Tsiaoussis ${ }^{c}$ \\ Anastasios Tzortzinis $^{d}$ Maria Tzardi ${ }^{b}$ M. Moutafidis ${ }^{a}$ Christos Dervenis ${ }^{e}$ \\ Evaghelos Xynos ${ }^{b}$
}

${ }^{\mathrm{a}}$ First Department of General Surgery, Athens Naval Hospital, ${ }^{\mathrm{b}}$ Medical School, University of Crete,

'Department of Surgery, 'Metropolitan Hospital', d'Department of General Surgery, Naval Hospital of Crete, and

eFirst Department of General Surgery, 'Agia Olga' Hospital of Athens, Greece

\section{Key Words}

Laparoscopy $\cdot$ Rectal cancer $\cdot$ Total mesorectal excision • Lymph node harvesting $\cdot$ Lymph node clearance

\begin{abstract}
Background: Laparoscopic resection of the rectum is still under scrutiny for its adequacy of oncological clearance. Aim: To assess lymph node yield after laparoscopic total mesorectal excision (TME) for rectal cancer as compared to the open approach. Methods: 74 patients with middle and low rectal cancer were prospectively randomized in two groups. Group A included 39 patients who had an open TME (35 with low anterior resection of the rectum (LARR) and 4 with abdominoperineal resection of the rectum (APR)). In group $B$, there were 34 patients who had a laparoscopic TME (27 with LARR and 7 with APR). 10 of the LARR patients in group $A$ and 14 of the LARR patients in group $B$ had a defunctioning ileostomy. All operations were performed by one surgeon or under his supervision. Results: Gender and age distribution were similar for both groups (group A: 23 males; mean age 69 (41-85); group B: 20 males; mean age 72 (31-84)). The
\end{abstract}

mean distance of the tumor from the dentate line was $7.6 \mathrm{~cm}$ $(1-12 \mathrm{~cm})$ for group A and $6.1 \mathrm{~cm}(1-12 \mathrm{~cm})$ for group B. Anastomosis was formed at a mean distance of $5.5 \mathrm{~cm}(1.5-8.5$ $\mathrm{cm})$ from the dentate line in group $A$ and $3.5 \mathrm{~cm}(1-4.5 \mathrm{~cm})$ in group B. At histology, in group A there were 5 T4 tumors, $9 \mathrm{~T} 3,10 \mathrm{~T} 3+(<1 \mathrm{~mm}$ distance from the circumferential resection margin), $13 \mathrm{~T} 2$ and $2 \mathrm{~T} 1$. In group $B$, there were $3 \mathrm{~T} 4 \mathrm{tu}$ mors, $14 \mathrm{~T} 3,8 \mathrm{~T} 3+, 7 \mathrm{~T} 2$ and $2 \mathrm{~T} 1$. Differences between groups were not significant. The mean number of lymph nodes retrieved in group A specimens was $19.2(5-45)$ and in group B $19.2(8-41)(p=0.2)$. In group A, $3.9(1-9)$ regional, 13.9 (3-34) intermediate and 1.5 (1-3) apical lymph nodes were retrieved. The respective values in group B were 3.7 (3-7), 14.4 (4-33) and 1.3 (1-3). Differences between groups were not significant. Also, the incidence of lymph node involvement by the tumor was not significantly different between groups (group A: 23; group B: 19). Conclusions: Laparoscopic resection of the rectum can achieve similar lymph node clearance to the open approach. Also, distribution of the lymph nodes along the resected specimens is similar between the two approaches.

Copyright $\odot 2007$ S. Karger AG, Basel

\section{KARGER}

Fax +4161306 1234 E-Mail karger@karger.ch www.karger.com (c) 2007 S. Karger AG, Basel

0257-2753/07/0251-0094\$23.50/0

Accessible online at: www.karger.com/ddi
Evaghelos Xynos

19, Michelidaki Street

GR-712 02 Heraklion (Greece)

Tel. +302810280002, Fax +302810280009

E-Mail exynos@med.uoc.gr 


\section{Introduction}

Standardization of mesorectal excision for rectal cancer as proposed by Heald et al. [1] undoubtedly resulted in lower local recurrence [2] and longer survival [3] rates as compared to conventional resection of the rectum. To date, there is evidence that laparoscopy for colorectal cancer offers the chance for a meticulous and easy dissection of the mesocolon and mesorectum under direct vision, in contrast to the 'touch-guided' open approach, particularly applied when dealing with the rectum. According to two recent meta-analyses $[4,5]$, there is enough evidence that laparoscopic surgery can achieve oncological clearance equal to the open approach for rectal cancer. The evidence presented is not strong, mostly because it is based on randomized trials with rather small number of patients included [6-8], one multicentric trial [9] and several cohort studies [10-25]. Multicentric trials carry the disadvantage of including operations performed by many surgeons with different and very often limited experience, thus outweighing the advantage of the large number of patients included and weakening the strength of the conclusions drawn. Both meta-analyses were unable to find enough evidence for long-term outcomes on cancer recurrence and survival. Furthermore, data concerning lymph node retrieval that derive from comparative studies are lacking. A randomized trial comparing the outcomes after either laparoscopic or conventional open surgery in patients with rectal cancer was set up in three surgical units. In the present study, the adequacy of oncological clearance as depicted by the number of lymph nodes retrieved is discussed.

\section{Methods}

\section{Patients}

All patients with low rectal carcinoma were randomly allocated to undergo total mesorectal excision (TME) on an intention-to-cure basis by either the open (group A) or the laparoscopic (group B) approach, in three surgical units. Randomization was performed by computer-generated numbers. Collected data included patients' demographics, clinical and imaging characteristics of the tumor, neoadjuvant treatment if given, type of surgical resection and anastomosis if performed, and histopathologic reports on the extent of tumor invasion, status of lymph nodes retrieved (number, location in relation to the tumor and possible infiltration by the tumor) and final TNM staging.
Tumor Clinical Characteristics and Preoperative Staging

Only rectal tumors located within the distal $12 \mathrm{~cm}$ from the anal verge were included in the study. Digital examination and rigid sigmoidoscopy were applied to assess tumor extent at the periphery of the rectum, distance from the anal verge and fixation. An anterior component of the tumor was specifically mentioned, as this necessitated the administration of neoadjuvant treatment irrespective of the extent of invasion. Staging of the tumor was achieved by pelvic MRI in all cases and occasionally by endorectal ultrasound.

Patients with an anteriorly located T2-T4 tumor, a T3 tumor with a $<5 \mathrm{~mm}$ free circumferential margin, lymph node involvement, venous invasion, and T4 or bulky locally advanced tumor were subjected to a high-dose radiotherapy and chemotherapy (total of 45 Gray and 5 -fluorouracil per os over 5 weeks), followed by surgery $8-10$ weeks later. Patients with tumors extending to the pelvic walls or organs were excluded from the study. Patients with anterior located T1, T2, and T3 tumors with a $>5 \mathrm{~mm}$ free circumferential margin were given a preoperative short hypofractionated scheme of radiotherapy (total of 25 Gray over 5 days) followed by surgery $10-15$ days later. The decision to perform either a low anterior resection of the rectum (LARR) with stapled colorectal anastomosis, or a LARR with intersphincteric resection and hand-sawn coloanal anastomosis, or an abdominoperineal resection (APR) was made prior to any downsizing of the tumor by the neoadjuvant treatment.

\section{Surgical Techniques}

All procedures were either performed or supervised by the most experienced surgeon. The first stage of the procedure, by either approach, involved ligation and division of the inferior mesenteric vein immediately below the Treitz ligament, and ligation and division of the inferior mesenteric artery at approximately $1 \mathrm{~cm}$ distal to its origin from the aorta, taking care to leave the hypogastric nerves intact behind, while clearing off the lymph nodes along the course of the vessel. Mobilization of the sigmoid and descending colon was carried out by the medial-tolateral fashion of dissection, in between the two leaves of Toldt's fascia.

In case of the LARR, the 'holy plane' between the pelvic and rectal fasciae posterior to the rectum was entered and developed distally to the rectosacral ligament, which was sharply divided. The hypogastric nerves were safely left behind. The peritoneum at both sides of the upper part of the rectum was incised, and the two lines of incision met anteriorly on the crest of the peritoneal reflection, at 1-2 cm anteriorly to the cul-de-sac. The space anteriorly to the Denonvillier's fascia at the mid-rectum and posteriorly to the seminal vesicles and prostate in male or vagina in female was entered. The Denonvilliers' fascia was transversely incised as it becomes adherent to the prostatic apex in male, or at the level of distal transaction of the rectum in female. Laterally, the lateral ligaments of the rectum were divided on their medial part, in order to preserve the hypogastric nerves. In case of intersphincteric resection, the fascia covering the levator ani was incised and the space between the anal sphincters and the bowel wall was entered. If a part of rectal stump was left in situ above the levator ani musculature, it was completely denuded posterior from the tail of the distal mesorectum. The vertical transection of the rectum distal to the tumor was achieved with the use of a linear stapling device, and a stapled colorectal anas- 
tomosis was fashioned. When an intersphincteric resection of the rectum was performed, distal transaction was carried out transanally and the specimen was exteriorized through the anus, and a hand-sewn coloanal anastomosis followed. The distance of the anastomotic line from the anal verge was measured by on-table anoscopy. A covering ileostomy was fashioned in almost all cases.

In case of an APR, posterior dissection ended at the level of the rectosacral ligament. At the perineal stage, the excision was carried out widely on the skin and involved the ischirectal fat and most of the bulk of the lavatory ani, covered orally by a plate of fascia. The excised specimen should appear at its distal part in the form of a 'cylinder' rather than having a 'waist' between the tail of the mesorectum and the anal sphincters [26]. In most instances, the perineal gap was covered with a biological prosthetic material, and the perineal skin was sutured over it.

\section{Histopathology Report on Lymph Nodes}

All lymph nodes in the specimen should be identified, dissected and embedded. At first, the apical lymph nodes, adjacent to the point of ligation of the vascular pedicle are dissected. Thereafter, the mesentery is cut at the mesenteric edge of the bowel wall, avoiding removal of any area in which subserosal fat tissue may be involved by the carcinoma. The mesentery is divided into three levels: the level proximal to the tumor that involves mesenteric tissue at a radius of $1 \mathrm{~cm}$, the intermediate level and the apical level. Then thin sections from each level are performed at $1-\mathrm{mm}$ intervals, and examined by careful palpation. Any firm tissue remaining after gentle pressure is isolated and considered as lymph node and embedded separately. All the lymph nodes are embedded in totality, including those with large dimensions.

Four sections of each lymph node are examined after hematoxylin and eosin staining. Extramural tumor deposits measuring $>3 \mathrm{~mm}$ are considered and counted as involved lymph nodes, even if no residual lymph node tissue can be identified.

\section{Statistical Analysis}

Statistical analysis was performed with the use of SPSS Version 11.5 software for Windows (SPSS, Chicago, Ill., USA). Values are expressed as median and range. Comparisons between the two groups of patients were made by applying either the Student $t$ test or the Mann-Whitney $U$ test for unpaired values, as appropriate. The $\chi^{2}$ test was applied to compare differences in variables expressed in proportions. Differences were considered to be significant for $\mathrm{p}$ values $<0.05$.

\section{Results}

Thirty-nine patients (23 male) with a median age of 69 (41-85) years were allocated in group A and $34(20$ male) with a mean age of $72(31-84)$ years in group B. Rectal tumors were located at a significantly higher level from the anal verge in group A than in group $B(8$ (1-12) $\mathrm{cm}$ vs. $6(1-12) \mathrm{cm} ; \mathrm{p}=0.03)$. In 10 cases in group $A$ and in 9 in group $\mathrm{B}$, the rectal tumor involved the anterior
Table 1. Preoperative staging of the tumor (T) based on MRI of the pelvis

\begin{tabular}{llc}
\hline & Group A & Group B \\
\hline T1 & 2 & 2 \\
T2 & 13 & 7 \\
T3 & $19(10)$ & $22(8)$ \\
T4 & 5 & 3 \\
\hline
\end{tabular}

The number of cases with a distance of $<5 \mathrm{~mm}$ from the circumferential margin is shown in parentheses rectal wall. Five cases in group A and 3 in group B had a T4 tumor. Ten patients in group A and 8 in group B had a T3 tumor in a distance $<5 \mathrm{~mm}$ from the circumferential margin of the mesorectum (table 1). Fewer patients in group A had T3/T4 tumors than in group B group (61.54 vs. $72.72 \%$ ), although the difference was not significant. Concerning the lymph nodes status, there were $24 \mathrm{~N} 0,10 \mathrm{~N} 1$, and $5 \mathrm{~N} 2$ cases in group A, and $28 \mathrm{~N} 0,3$ $\mathrm{N} 1$ and $2 \mathrm{~N} 2$ cases in group $\mathrm{B}$. Thus, based on preoperative staging, 17 patients in group $A$ and 13 group $B$ were given neoadjuvant treatment (group A: 4 short scheme radiation, 13 long scheme chemoradiation; group B: 3 short scheme radiation, 10 long scheme chemoradiation).

Significantly more cases in group B had intersphincteric resection and abdominoperineal resection of the rectum than in group A $(\mathrm{p}=0.04)$. Also, colorectal or anal anastomoses were significantly lower in group B than in group $A$ (mean distance from dentate line: group B: $3.5(1-4.5) \mathrm{cm}$ vs. group A: $5.5(1.5-8.5) \mathrm{cm} ; \mathrm{p}<0.001)$. Conceivably, a significantly larger number of patients after laparoscopy had a protecting ileostomy $(\mathrm{p}=0.04)(\mathrm{ta}-$ ble 2). There was one conversion of laparoscopy to open surgery (3\%), because of tumor fixation to the right lateral pelvic wall. No specific technical difficulties nor greater blood loss were accounted in patients with neoadjuvant treatment after either approach, as compared to those without.

There was no significant difference in the total number of retrieved lymph nodes between groups (group A: $19.2(5-45)$; group B: $19.2(8-41)(\mathrm{p}=0.2))$. Also, the numbers of regional, intermediate and apical lymph nodes did not differ significantly between groups. In 19 patients of group A and 23 of group B, lymph nodes had metastatic deposits (table 3 ). 
Table 2. Operative details

\begin{tabular}{lcc}
\hline & Group A & Group B \\
\hline Total number of patients & 39 & 34 \\
Type of surgery & & \\
$\quad$ Low anterior resection of rectum & 34 & 22 \\
$\quad$ Intersphincteric resection of rectum & 1 & 5 \\
$\quad$ Abdominoperineal resection of rectum & 4 & 7 \\
Distance of anastomosis from anal verge, cm (range) & $5.5(1.5-8.5)$ & $4(1-4.5)$ \\
Protective ileostomy, n (\%) & $10(26)$ & $14(42)$ \\
\hline
\end{tabular}

Table 3. Histological characteristics of lymph nodes

\begin{tabular}{lcc}
\hline & Group A & Group B \\
\hline Lymph nodes, n (range) & $19.2(5-45)$ & $19.2(8-41)$ \\
Regional & $3.9(1-9)$ & $3.7(3-7)$ \\
Intermediate & $13.9(3-34)$ & $14.4(4-33)$ \\
Apical & $1.5(1-3)$ & $1.3(1-3)$ \\
\hline Lymph node infiltration & & \\
Positive & 19 & 23 \\
Negative & 20 & 11 \\
\hline
\end{tabular}

\section{Discussion}

Laparoscopy has been easily adopted for colon surgery, but is slowly gaining acceptance by the surgical community for rectal cancer. This is because of the initial concerns about adequacy of free resection margins and lymph node retrieval, while performing a TME for middle and low rectal cancer. Two recently published metaanalyses show that laparoscopic rectal cancer surgery may accomplish an oncological clearance of similar quality to the open approach $[4,5]$. Of the 23 studies included in those meta-analyses, only 4 were randomized trials, 3 from a single institution with small number of patients [6-8] and 1 multicentric [9]. The evidence of adequate oncological clearance provided by those studies is rather weak, because of methodological drawbacks. In addition, an adequate oncological clearance for rectal cancer should be reflected in the long-term outcomes, namely local recurrence and survival. But again, existing evidence derived from the above studies is weak. This is because the large statistical power of multicenter trials is overwhelmed by the inhomogeneous adjuvant and neoadjuvant regimens applied by participating teams and the varying degree of experience of the surgeons practicing laparoscopic rectal surgery. Inadequate experience is illustrated at the conversion rate of laparoscopic resection of the rectum, which in the recently published multicenter CLASICC trial is as high as 34\% [9]. On the contrary, the quality of surgery is high and the conversion rate very low in two published series of laparoscopic rectal resection, where only very experienced surgeons were involved [27, 28]. Also, recurrence and overall survival in these two series is similar to those reported by the best performers of the open approach $[1,2]$. More homogenous comparative studies, namely prospective randomized trials conducted by a single experienced surgical team with a uniform updated oncological approach in terms of neoadjuvant and adjuvant treatment, will provide more solid evidence on the oncological safety of the laparoscopic approach for rectal cancer.

The meta-analysis by Aziz et al. [4] including 1,375 patients from 17 studies shows no significant differences in the proportion of patients with positive radial margins and the number of lymph nodes harvested between laparoscopic and open LARR or APR for rectal cancer surgery. Of the six studies reporting on lymph node retrieval included in the meta-analysis by Gao et al. [5], five report no difference in lymph node numbers removed with the specimen between the open and the laparoscopic resection of the rectum; in only one study by Araujo et 
al. [7], the number of lymph nodes retrieved by the open approach was significantly larger than that by laparoscopy.

Because it has been shown that many nodal metastases in colorectal cancer are found in small lymph nodes of $<5 \mathrm{~mm}$ in diameter and that a minimum of 12-18 lymph nodes must be examined, a very careful search for lymph nodes must be performed $[29,30]$. These criteria have been fulfilled at histology in the present study, the results of which showed no significant difference in the number of lymph nodes harvested by either the open or the laparoscopic approach. Furthermore, there were no differences whatsoever in the distribution of lymph nodes along the specimens; mean numbers of regional, intermediate and apical lymph nodes retrieved were similar between the two approaches. In this sense, laparoscopy seems to be of equal lymph node sampling capacity to the open approach, provided that all other aspects of an adequate quality of surgery are fulfilled by both approaches [31].
Rectal tumors in the laparoscopic group of the present study were located to a significantly lower level. This resulted in lower anastomoses and larger numbers of APR and intersphincteric resections undertaken compared to open surgery. However, cases with a threatened circumferential margin on preoperative imaging and final TN staging of the disease did not differ between the two approaches. None of these macroscopic or histological parameters seemed to affect the number of lymph nodes retrieved.

In conclusion, laparoscopic resection of the rectum achieves similar lymph node number retrieval with similar lymph node distribution along the resected specimen to the open approach, offering adequate sampling capacity. Lymph node clearance must be combined with other histological parameters so as to ensure that laparoscopic resection of the rectum is an approach that provides resection specimens of as high quality as the conventional open procedure.

\section{References}

1 Heald RJ, Husband EM, Ryall RDH: The mesorectum in rectal cancer surgery: the clue to pelvic recurrence? Br J Surg 1982;69:613616.

-2 Heald RJ, Karanjia ND: Results of radical surgery for rectal cancer. World J Surg 1992; 16: 848-857.

3 Dahlberg M, Glimelius B, Pahlman L: Changing strategy for rectal cancer is associated with improved outcome. Br J Surg 1999; 86:379-384.

4 Aziz O, Constantinides V, Tekkis PP, et al: Laparoscopic versus open surgery for rectal cancer: a meta-analysis. Ann Surg Oncol 2006;13:413-424.

5 Gao F, Cao YF, Chen LS: Meta-analysis of the short-term outcomes after laparoscopic resection for rectal cancer. Int J Colorectal Dis 2006;7:1-5.

-6 Quah HM, Jayne DG, Eu KW, Seow-Choen F: Bladder and sexual dysfunction following laparoscopically assisted and conventional open mesorectal resection for rectal cancer. Br J Surg 2002;89:1551-1556.

7 Araujo SE, da Silva e Sousa AH Jr, de Campos FG, et al: Conventional approach versus laparoscopic abdominoperineal resection for rectal cancer treatment after neoadjuvant chemoradiation: results of a prospective randomized trial. Rev Hosp Clin Fac Med São Paolo 2003;58:133-140.

\footnotetext{
8 Breukink SO, Grond AJK, Pierie JPEN, Hoff C, Wiggers T, Meijerink WJHJ: Laparoscopic vs. open total mesorectal excision for rectal cancer. An evaluation of the mesorectum's macroscopic quality. Surg Endosc 2005; 19:307-310.

-9 Guillou PJ, Quirke P, Thorpe H, et al: Shortterm endpoints of conventional versus laparoscopic assisted surgery in patients with colorectal cancer (MRC CLASICC trial): multicentre, randomised controlled trial. Lancet 2005;365:1718-1726.

10 Tate JJ, Kwok S, Dawson JW, et al: Prospective comparison of laparoscopic and conventional anterior resection. Br J Surg 1993;80: 1396-1398.

11 Darzi A, Lewis C, Menzies-Gow N, et al: Laparoscopic abdominoperineal excision of the rectum. Surg Endosc 1995;9:414-417.

12 Goh YC, Eu KW, Seow-Choen F: Early postoperative results of a prospective series of laparoscopic vs. open anterior resections for rectosigmoid cancers. Dis Colon Rectum 1997;40:776-780.

13 Leung KL, Kwok SP, Lau WY, et al: Laparoscopic-assisted resection of rectosigmoid carcinoma. Immediate and medium-term results. Arch Surg 1997;132:761-764.

14 Seow-Choen F, Eu KW, Ho YH, Leong AF: A preliminary comparison of a consecutive series of open versus laparoscopic abdominoperineal resection for rectal adenocarcinoma. Int J Colorectal Dis 1997;12:88-90.
Ramos JR, Petrosemolo RH, Valory EA, et al Abdominoperineal resection: laparoscopic versus conventional. Surg Laparosc Endosc 1997;7:148-152.

16 Iroatulam AJ, Agachan F, Alabaz O, et al: Laparoscopic abdominoperineal resection for anorectal cancer. Am Surg 1998;64:1218.

17 Fleshman JW, Wexner SD, Anvari M, et al: Laparoscopic vs. open abdominoperineal resection for cancer. Dis Colon Rectum 1999; 42:930-939.

-18 Schwandner O, Schiedeck TH, Killaitis C, Bruch HP: A case-control-study comparing laparoscopic versus open surgery for rectosigmoidal and rectal cancer. Int J Colorectal Dis 1999;14:158-163.

19 Leung KL, Kwok SP, Lau WY, et al: Laparoscopic-assisted abdominoperineal resection for low rectal adenocarcinoma. Surg Endosc 2000;14:67-70.

20 Hartley JE, Mehigan BJ, Qureshi AE, et al: Total mesorectal excision: assessment of the laparoscopic approach. Dis Colon Rectum 2001;44: 315-321.

21 Baker RP, White EE, Titu L, et al: Does laparoscopic abdominoperineal resection of the rectum compromise long-term survival? Dis Colon Rectum 2002;45:1481-1485.

22 Anthuber M, Fuerst A, Elser F, et al: Outcome of laparoscopic surgery for rectal cancer in 101 patients. Dis Colon Rectum 2003; 46:1047-1053.
} 
23 Feliciotti F, Guerrieri M, Paganini AM, et al: Long-term results of laparoscopic versus open resections for rectal cancer for 124 unselected patients. Surg Endosc 2003;17:15301535.

24 Vorob'ev GI, Shelygin IuA, Frolov SA, et al: Laparoscopic surgery of rectal cancer (comparative results of laparoscopic and open abdominal resection) (in Russian). Khirurgiia (Mosk) 2003;3:36-42.

25 Wu WX, Sun YM, Hua YB, Shen LZ: Laparoscopic versus conventional open resection of rectal carcinoma: a clinical comparative study. World J Gastroenterol 2004;10:11671170 .
26 Radcliffe A: Can the results of anorectal (abdominoperineal resection) be improved: are circumferential resection margins too often positive? Colorectal Dis 2006;8:160-167.

$>27$ Morino M, Parini U, Giraudo G, Salval M, Brachet Contul R, Garonne C: Laparoscopic total mesorectal excision: a consecutive series of 100 patients. Ann Surg 2003;237:335342.

28 Leroy J, Jamali F, Forbes L, et al: Laparoscopic total mesorectal excision for rectal cancer surgery: long-term outcomes. Surg Endosc 2004;18:281-289.
29 Jass JR, Morson BC: Reporting colorectal cancer. J Clin Pathol 1987;40:1016-1023.

30 Carolyn C, Compton CA: The staging of colorectal Cancer: 2004 and beyond. Cancer J Clin 2004;54:295-308.

31 Nagtegaal ID, van de Velde CJ, van der Worp E, Kapiteijn E, Quirke P, van Krieken JH, Cooperative Clinical Investigators of the Dutch Colorectal Cancer Group: Macroscopic evaluation of rectal cancer resection specimen: clinical significance of the pathologist in quality control. J Clin Oncol 2002;20:17291734. 